\title{
Genomic expression profiling and bioinformatics analysis of pancreatic cancer
}

\author{
DONG-YAN HAN ${ }^{*}$, DA FU* ${ }^{*}$ HAO XI, QIAN-YU LI, LI-JIN FENG, \\ WEI ZHANG, GUO JI, JIA-CHENG XIAO and QING WEI \\ Department of Pathology, Shanghai Tenth People's Hospital, Shanghai 200072, P.R. China
}

Received September 6, 2014; Accepted May 13, 2015

DOI: $10.3892 / \mathrm{mmr} .2015 .3917$

\begin{abstract}
Pancreatic cancer is a polygenic disease and the fourth leading cause of cancer-associated mortality worldwide; however, the tumorigenesis of pancreatic cancer remains poorly understood. Research at a molecular level, which includes the exploration of biomarkers for early diagnosis and specific targets for therapy, may effectively aid in the diagnosis of pancreatic cancer in its early stages and in the development of targeted molecular-biological approaches for treatment, thus improving prognosis. By conducting expression profiling in para-carcinoma, carcinoma and relapse of human pancreatic tissues, 319 genes or transcripts with differential expression levels $>3$-fold between these tissue types were identified. Further analysis with Gene Ontology and the Kyoto Encyclopedia of Genes and Genomes demonstrated that the translation, nucleus assembly processes and molecular functions associated with vitamin B6 and pyridoxal phosphate binding in pancreatic carcinoma were abnormal. Pancreatic cancer was additionally identified to be closely associated with certain autoimmune diseases, including type I diabetes mellitus and systemic lupus erythematosus.
\end{abstract}

\section{Introduction}

Pancreatic cancer is globally the fourth leading cause of cancer-associated mortality for men and women, based on incidence and mortality statistics. There were 337,872 novel pancreatic cancer cases reported and 330,372 cases of pancreatic cancer-associated mortality in 2012, accounting for $2.4 \%$ of the annual novel cancer cases in 2012 and ranking as the

Correspondence to: Dr Qing Wei, Department of Pathology, Shanghai Tenth People's Hospital, 301 Middle Yanchang Road, Shanghai 200072, P.R. China

E-mail: dr_weiqing@126.com

*Contributed equally

Key words: pancreatic cancer, gene expression profiling, DNA microarray, type I diabetes mellitus, systemic lupus erythrmatosus 12th most prevalent cancer worldwide (Globocan 2012; http:// globocan.iarc.fr/Pages/fact_sheets_population.aspx). The average life expectancy upon diagnosis is between four and eight months, and individuals undergoing surgery to remove the carcinoma have an $\sim 30 \%$ five-year survival rate (1). However, due to late diagnosis, only $10 \%$ of diagnosed patients are eligible for potentially curative surgery (1). Due to the fact that the causes of pancreatic cancer remain to be fully elucidated and no specific symptoms have been identified for early-stage diagnosis, pancreatic cancer remains difficult to diagnose.

Pancreatic cancer is a polygenic disease, as are the majority of cancer types $(2,3)$. The accumulation of multiple genetic defects has an effect on tumorigenesis (4). The arrival and advancement of DNA microarray technology make it possible to monitor the expression levels of a vast number of genes or transcripts in a single microchip. Thus, microarray technology has become a key tool in the investigation of key genes associated with the progression of this malignancy. Gene expression profiling, which is based on DNA microarray technology, has allowed for the identification of hundreds of genes with differential expression in pancreatic carcinoma (5). Genes with the most up/downregulated expression levels in pancreatic carcinoma are p16, p53, K-ras and Smad4, as previously reported (6). These genes are suggested to serve as predictive biomarkers for early diagnosis. Bioinformatics analysis allows for the mapping of genes with differential expression levels to metabolic or signalling pathways, which may provide potential targets for the design of novel anti-cancer drugs (7). The Ras signaling pathway, for example, has attracted attention as an anti-cancer drug target, due to its important function in tumorigenesis (8). For pancreatic cancer, Wnt (9), Notch (10) and Hedgehog (11) pathways have been additionally identified as being of marked significance.

Given the complexity of the genome, it is suggested that numerous genes associated with pancreatic cancer have remained to be identified. Thus, the present study aimed to investigate and enhance the understanding of the underlying molecular mechanisms of pancreatic cancer by undertaking gene expression profiling on a pancreatic carcinoma sample in Shanghai, China. Human whole genome microarray analysis was used to identify the differentially expressed genes between para-carcinoma, carcinoma and relapse human pancreatic cancer tissues. 


\section{Materials and methods}

Tissue samples. The para-carcinoma, carcinoma and relapse pancreatic carcinoma tissues were obtained from a patient (46 years old, female, stage II) undergoing cancer resection at Shanghai Tenth People's Hospital (Shanghai, China). Written informed consent was obtained from the patient and ethical approval of the present study was obtained from the ethical committee of Shanghai Tenth People's Hospital (Shanghai, China).

RNA extraction. RNA samples from matched para-carcinoma, carcinoma and relapse pancreatic carcinoma tissues were extracted using TRIzol reagent (Invitrogen Life Technologies, Carlsbad, CA, USA). A total of $1 \mathrm{ml}$ TRIzol was used for every $100 \mathrm{mg}$ tissue. Total RNA was isolated using phenol/chloroform (Sinopharm Chemical Reagent Co., Ltd, Shanghai, China) according to the manufacturer's instructions. Subsequent to the precipitation of RNA, 75\% (v/v) ethanol was used to wash out the salts. The RNA was then air-dried and dissolved in RNase-free water. The quality and quantity of total RNA was determined using a NanoDrop 2000 (Thermo Fisher Scientific, Waltham, MA, USA).

Microarray assay. The Agilent Microarray Platform (Agilent Technologies, Inc., Santa Clara, CA, USA) was used to conduct the microarray analysis. Sample preparation and the follow-up hybridization were performed according to the manufacturer's instructions. Total RNA $(1 \mu \mathrm{g})$ was extracted from each sample as mentioned above, and the Agilent Quick Amp Labeling kit (protocol version 5.7; Agilent Technologies, Inc.) was used to amplify and transcribe the RNA into fluorescent cRNA following the manufacturer's instructions. Sample labeling was performed using the Agilent Quick Amp Labeling kit, while subsequent hybridization was performed in SureHyb Hybridization Chambers (Agilent Technologies, Inc.). The labelled cRNA was then hybridized onto the Whole Human Genome Oligo Microarray (4x44 K; Agilent Technologies, Inc.). Arrays were scanned with the G2505B Scanner (Agilent Technologies, Inc.) subsequent to washing of the slides.

Data analysis. The acquired array images were analyzed with Agilent Feature Extraction software, version 10.7.3.1, while GeneSpring GX software, version 11.5.1 (Agilent Technologies, Inc.) was used for quantile normalization and data processing.

Among the 45,000 genes or transcripts included in the microarray, 7,937 genes or transcripts with valid values detected in all three groups measured (carcinoma, para-carcinoma and relapse tissues) were used for the subsequent analysis. Genes with differential expression levels in different tissues were identified by fold-change filtering. Expression levels of genes were normalized by $\log 2$ transformation for the subsequent analysis. Pairwise comparisons were completed between the expression levels of the same gene or transcript in any two tissues. Genes or transcripts exhibiting fold-changes $>1.5$ - and 3 -fold in expression levels in a minimum of one pairwise comparison were selected for further analysis, and bioinformatics analysis was conducted on the genes or transcripts with alterations in expression levels of $>3$-fold.
Analysis results from Gene Ontology (GO) and Kyoto Encyclopedia of Gene and Genomes (KEGG; http://www.genome.jp/kegg/) databases were gathered and enriched by using the online Database for Annotation, Visualization and Integrated Discovery server (DAVID; http://david.abcc.ncifcrf.gov/) with the standard enrichment computation method (12).

\section{Results}

Microarray analysis. The microarray assay was qualified according to quality standards, the experimental systems were observed to be stable and the fluorescent signal intensity was strong and homogenous (Fig. 1). cRNAs were hybridized onto the Whole Human Genome Oligo Microarray and 7,937 probes exhibited clear signals in all three chips simultaneously, representing $17.63 \%$ of the 45,000 probes assessed. Subsequent to differential expression level analysis, genes or transcripts corresponding to $3,298 / 7,937$ probes were observed to exhibit alterations in expression levels of $>1.5$-fold. Among these, 319 genes or transcripts were observed to have a fold change of $\geq 3$-fold.

Gene ontology analysis. A total of 319 genes or transcripts associated with pancreatic cancer were observed to exhibit $a \geq 3$-fold change in expression levels in the present study. Subsequently, the GO database was used to analyze these genes and DAVID was used for the enrichment terms.

A total of 23 functional description nodes were identified to be associated with biological processes, with $\mathrm{P}<0.01$ (Table I). According to their P-values (low-high), the top five terms were: Translational elongation, translation, nucleosome assembly, chromatin assembly and protein-DNA complex assembly. All of these terms were associated with cell metabolic processes. In addition, terms which are involved in immune response and metal ion metabolic processes were observed.

Furthermore, 26 functional description nodes were identified to be associated with cellular components, with $\mathrm{P}<0.01$ (Table II). The top five terms were identified to be: Cytosolic ribosome, ribosomal subunit, cytosolic small ribosomal subunit, cytosolic part and small ribosomal subunit.

Finally, 7 functional description nodes were identified to be associated with molecular function, with $\mathrm{P}<0.01$. These nodes were: Structural constituent of ribosome, structural molecule activity, protein binding, pyridoxal phosphate binding, vitamin B6 binding, binding and cadmium ion binding (Table III).

KEGG pathway analysis. KEGG pathway analysis was conducted on genes with an alteration in expression levels of $>3$-fold between the carcinoma, para-carcinoma and relapse human pancreatic cancer tissues. Of these, the genes associated with systemic lupus erythematosus (SLE) and type I diabetes mellitus are presented (Table IV). In systemic lupus erythematosus, 11 key genes were differentially expressed between carcinoma, para-carcinoma and relapse tissue, including: HLA-DPB1, HIST1H4J, HIST1H2BO, H3F3C, H2AFY, H3F3A, HIST2H3D, HIST1H4D, HIST2H4B, HIST1H2BL and HIST1H4K (Fig. 2, Table V). In type I diabetes mellitus, 
Table I. Gene ontology analysis of differentially expressed genes associated with biological processes.

\begin{tabular}{|c|c|c|c|}
\hline Term & Gene count (n) & $\%^{\mathrm{a}}$ & P-value \\
\hline Translational elongation & 16 & 7.2398190 & $9.70 \times 10^{-13}$ \\
\hline Translation & 18 & 8.1447964 & $4.72 \times 10^{-7}$ \\
\hline Nucleosome assembly & 8 & 3.6199095 & $6.50 \times 10^{-5}$ \\
\hline Chromatin assembly & 8 & 3.6199095 & $8.14 \times 10^{-5}$ \\
\hline Protein-DNA complex assembly & 8 & 3.6199095 & $1.08 \times 10^{-4}$ \\
\hline Nucleosome organization & 8 & 3.6199095 & $1.24 \times 10^{-4}$ \\
\hline Response to metal ion & 9 & 4.0723982 & $1.60 \times 10^{-4}$ \\
\hline $\begin{array}{l}\text { Antigen processing and presentation } \\
\text { of peptide antigen }\end{array}$ & 5 & 2.2624434 & $3.24 \times 10^{-4}$ \\
\hline Antigen processing and presentation & 7 & 3.1674208 & $4.75 \times 10^{-4}$ \\
\hline DNA packaging & 8 & 3.6199095 & $5.12 \times 10^{-4}$ \\
\hline Response to stimulus & 62 & 28.054299 & $6.66 \times 10^{-4}$ \\
\hline Response to inorganic substance & 10 & 4.5248869 & $8.13 \times 10^{-4}$ \\
\hline Chromatin assembly or disassembly & 8 & 3.6199095 & $8.35 \times 10^{-4}$ \\
\hline $\begin{array}{l}\text { Antigen processing and presentation of } \\
\text { peptide antigen via MHC class I }\end{array}$ & 4 & 1.8099548 & 0.00101320 \\
\hline Immune response & 19 & 8.5972851 & 0.00156179 \\
\hline Negative regulation of apoptosis & 12 & 5.4298643 & 0.00359381 \\
\hline Negative regulation of programmed cell death & 12 & 5.4298643 & 0.00399353 \\
\hline Negative regulation of cell death & 12 & 5.4298643 & 0.00407759 \\
\hline Response to calcium ion & 5 & 2.2624434 & 0.00420590 \\
\hline Iron ion transport & 4 & 1.8099548 & 0.00490087 \\
\hline Regulation of calcium ion transport into cytosol & 4 & 1.8099548 & 0.00490087 \\
\hline Response to chemical stimulus & 27 & 12.217195 & 0.00526131 \\
\hline Ribosomal small subunit biogenesis & 3 & 1.3574661 & 0.00730011 \\
\hline
\end{tabular}

aPercentage of the counted genes among all the genes with a $>3$-fold change in expression level. MHC, major histocompatibility complex.
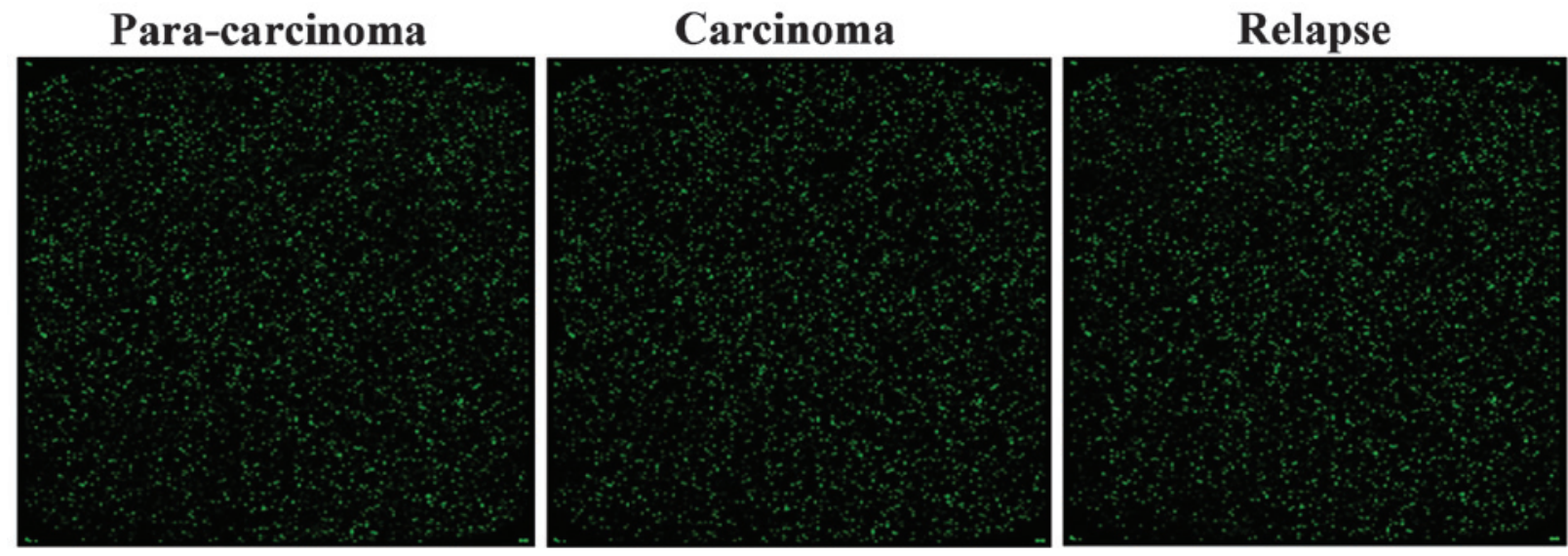

Figure 1. Gene chip hybridization fluorescence signal image in para-carcinoma, carcinoma and relapse tissues of human pancreatic cancer.

HLA-A, HLA-B, HLA-C, HLA-DPB1 and GAD1 (Fig. 3, Table VI) exhibited significantly different expression levels.

\section{Discussion}

Pancreatic cancer is a lethal malignancy with few effective therapies currently available (13). It is the fourth leading cause of cancer-associated mortality, with an overall five-year survival rate of $<5 \%$ (14), which has remained unaltered for 50 years. With the availability of DNA microarray and next generation sequencing, it is now possible to study diseases, including various types of cancer, at the 'omic' level (15). DNA microarray gene expression profiling has previously been successfully applied in large-scale analyses of differentially 
Table II. Gene ontology analysis of differentially expressed genes associated with cellular components.

\begin{tabular}{|c|c|c|c|}
\hline Term & Gene count $(n)$ & $\%^{\mathrm{a}}$ & P-value \\
\hline Cytosolic ribosome & 18 & 0.0814480 & $2.07 \times 10^{-17}$ \\
\hline Ribosomal subunit & 18 & 0.0814480 & $6.53 \times 10^{-14}$ \\
\hline Cytosolic small ribosomal subunit & 12 & 0.0542986 & $4.40 \times 10^{-13}$ \\
\hline Cytosolic part & 18 & 0.0814480 & $1.16 \times 10^{-12}$ \\
\hline Small ribosomal subunit & 13 & 0.0588235 & $4.31 \times 10^{-12}$ \\
\hline Ribosome & 19 & 0.0859729 & $3.42 \times 10^{-11}$ \\
\hline Ribonucleoprotein complex & 23 & 0.1040724 & $7.30 \times 10^{-8}$ \\
\hline Macromolecular complex & 63 & 0.2850679 & $1.83 \times 10^{-6}$ \\
\hline Nucleosome & 8 & 0.0361991 & $6.37 \times 10^{-6}$ \\
\hline Cytosol & 34 & 0.1538462 & $1.09 \times 10^{-5}$ \\
\hline Protein-DNA complex & 8 & 0.0361991 & $4.98 \times 10^{-5}$ \\
\hline Cytoplasmic part & 79 & 0.3574661 & $1.53 \times 10^{-4}$ \\
\hline Cytoplasm & 107 & 0.4841629 & $1.81 \times 10^{-4}$ \\
\hline Non-membrane-bounded organelle & 49 & 0.2217195 & $2.04 \times 10^{-4}$ \\
\hline Intracellular non-membrane-bounded organelle & 49 & 0.2217195 & $2.04 \times 10^{-4}$ \\
\hline MHC class I protein complex & 5 & 0.0226244 & $2.52 \times 10^{-4}$ \\
\hline Intracellular part & 141 & 0.6380090 & $3.21 \times 10^{-4}$ \\
\hline MHC protein complex & 6 & 0.0271493 & $4.34 \times 10^{-4}$ \\
\hline Intracellular & 144 & 0.6515837 & $4.91 \times 10^{-4}$ \\
\hline Cytosolic large ribosomal subunit & 5 & 0.0226244 & $8.31 \times 10^{-4}$ \\
\hline Organelle part & 68 & 0.3076923 & $8.84 \times 10^{-4}$ \\
\hline Intracellular organelle & 122 & 0.5520362 & 0.0010071 \\
\hline Organelle & 122 & 0.5520362 & 0.0010775 \\
\hline Intracellular organelle part & 67 & 0.3031674 & 0.0012716 \\
\hline Chromatin & 9 & 0.0407240 & 0.0018679 \\
\hline Large ribosomal subunit & 5 & 0.0226244 & 0.0067159 \\
\hline
\end{tabular}

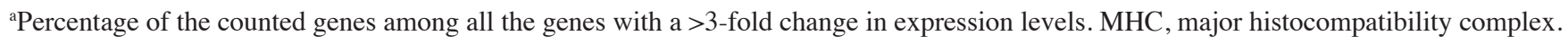

Table III. Gene ontology analysis of differentially expressed genes associated with molecular function.

\begin{tabular}{lccc}
\hline Term & Gene count (n) & $\%^{\mathrm{a}}$ & P-value \\
\hline Structural constituent of ribosome & 17 & 0.0769231 & $8.56 \times 10^{-11}$ \\
Structural molecule activity & 21 & 0.0950226 & $3.80 \times 10^{-5}$ \\
Protein binding & 118 & 0.5339367 & $1.44 \times 10^{-4}$ \\
Pyridoxal phosphate binding & 5 & 0.0226244 & 0.0033357 \\
Vitamin B6 binding & 5 & 0.0226244 & 0.0033357 \\
Binding & 157 & 0.7104072 & 0.0041273 \\
Cadmium ion binding & 3 & 0.0135747 & 0.0054982
\end{tabular}

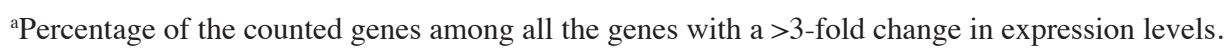

expressed genes involved in tumorigenesis (16). Gene expression profiling has previously been used in numerous studies focusing on pancreatic cancer. Chang et al (17) demonstrated that 3,853 genes displayed differential expression by $>1.5$-fold in pancreatic carcinoma tissue. Of these genes, the expression levels of 2,512 genes were upregulated and 1,341 genes were downregulated. Nakamura et al (18) identified 260 upregulated and 346 downregulated genes involved in pancreatic cancer.

In the present study, the gene expression levels between carcinoma, relapse carcinoma and para-carcinoma of human pancreatic cancer tissues were compared. Differentially expressed genes were observed and analyzed using GO term and KEGG pathway enrichment analysis. 
Table IV. KEGG pathway analysis results.

\begin{tabular}{|c|c|c|c|c|c|c|}
\hline $\begin{array}{l}\text { KEGG } \\
\text { pathway ID }\end{array}$ & Pathway name & $\begin{array}{c}\text { Gene } \\
\text { count (n) }\end{array}$ & $\begin{array}{l}\text { Percentage of } \\
\text { counted genes }\end{array}$ & NCBI gene ID & $\begin{array}{l}\text { Fold } \\
\text { enrichment }\end{array}$ & P-value \\
\hline hsa05322 & $\begin{array}{l}\text { Systemic lupus } \\
\text { erythematosus }\end{array}$ & 11 & $4.977 \%$ & $\begin{array}{c}3115,8363,8348,440093 \\
9555,3020,653604,8360 \\
554313,8340,8362\end{array}$ & 4.565656 & 0.001602 \\
\hline hsa04940 & $\begin{array}{c}\text { Type I diabetes } \\
\text { mellitus }\end{array}$ & 5 & $2.262 \%$ & $\begin{array}{c}2571,3115,3107 \\
3105,3106\end{array}$ & 5.380952 & 0.036427 \\
\hline
\end{tabular}

KEGG, Kyoto Encyclopedia of Genes and Genomes; NCBI, National Center for Biotechnology Information; hsa, Homo sapiens.

Table V. Genes with >3-fold change in expression levels in pancreatic cancer associated with systemic lupus erythematosus.

\begin{tabular}{lllcll}
\hline Gene ID & Gene symbol & fcCP & fcRP & fcCR & Description \\
\hline 3115 & HLA-DPB1 & 0.603255 & 1.960175 & 0.307756 & $\begin{array}{l}\text { Major histocompatibility complex, } \\
\text { class II, DP beta 1 }\end{array}$ \\
8363 & HIST1H4J & 0.308301 & 0.880094 & 0.350304 & Histone cluster 1, h4j \\
8348 & HIST1H2BO & 0.368137 & 1.208018 & 0.304744 & Histone cluster $1, \mathrm{~h} 2 \mathrm{bo}$ \\
440093 & H3F3C & 0.719753 & 3.972665 & 0.181176 & H3 histone, family 3C \\
9555 & H2AFY & 1.356658 & 0.260470 & 5.208496 & H2A histone family, member Y \\
3020 & H3F3A & 0.298552 & 0.615353 & 0.485173 & H3 histone, family 3A \\
653604 & HIST2H3D & 0.296694 & 0.722873 & 0.410437 & Histone cluster 2, h3d \\
8360 & HIST1H4D & 0.421040 & 1.396684 & 0.301457 & Histone cluster 1, h4d \\
554313 & HIST2H4B & 0.333331 & 0.730559 & 0.456268 & Histone cluster 2, h4b \\
8340 & HIST1H2BL & 0.224496 & 0.710622 & 0.315914 & Histone cluster $1, \mathrm{~h} 2 \mathrm{bl}$ \\
8362 & HIST1H4K & 0.335573 & 1.021847 & 0.328399 & Histone cluster $1, \mathrm{~h} 4 \mathrm{k}$
\end{tabular}

$\mathrm{fcCP}$, fold change of expression levels of genes in carcinoma tissue compared with that in para-carcinoma tissue; fcRP, fold change of expression levels of genes in relapse tissue compared with that in para-carcinoma tissue; fcCR, fold change of expression levels of genes in carcinoma tissue compared with that in relapse tissue.

Table VI. Genes with >3-fold change in expression levels in pancreatic cancer associated with type I diabetes mellitus.

\begin{tabular}{lcccll}
\hline Gene ID & Gene symbol & fcCP & fcRP & fcCR & Description \\
\hline 2571 & GAD1 & 1.062045 & 4.264469 & 0.249045 & Glutamate decarboxylase 1 \\
3115 & HLA-DPB1 & 0.603255 & 1.960175 & 0.307756 & Major histocompatibility complex, class II, DP beta 1 \\
3105 & HLA-A & 0.312182 & 0.491002 & 0.635806 & Major histocompatibility complex, class I, A \\
3106 & HLA-B & 0.299524 & 0.644979 & 0.464393 & Major histocompatibility complex, class I, B \\
3107 & HLA-C & 0.330177 & 0.661858 & 0.498863 & Major histocompatibility complex, class I, C \\
\hline
\end{tabular}

$\mathrm{fcCP}$, fold change of expression levels of genes in carcinoma tissue compared with that in para-carcinoma tissue; fcRP, fold change of expression levels of genes in relapse tissue compared with that in para-carcinoma tissue; fcCR, fold change of expression levels of genes in carcinoma tissue compared with that in relapse tissue.

Using GO term analysis, differentially expressed genes were observed in the present study, which were identified to be involved in biological processes and associated with translation, the nucleus and chromatin assembly. This is consistent with the knowledge that the nuclei in carcinoma cells are misshapen and enlarged (19). In the cellular component domain, the majority of the enriched terms were associated with the ribosomes. In the
GO analysis domain of molecular function, terms regarding the structural constitution of ribosomes and protein binding were highlighted. Of note, differentially expressed genes identified to be associated with molecular function included terms of pyridoxal phosphate (PLP) and vitamin B6 binding, and PLP is the active form of vitamin B6 (20). Johansson et al (21) reported that the serum vitamin B6 levels were inversely associated 


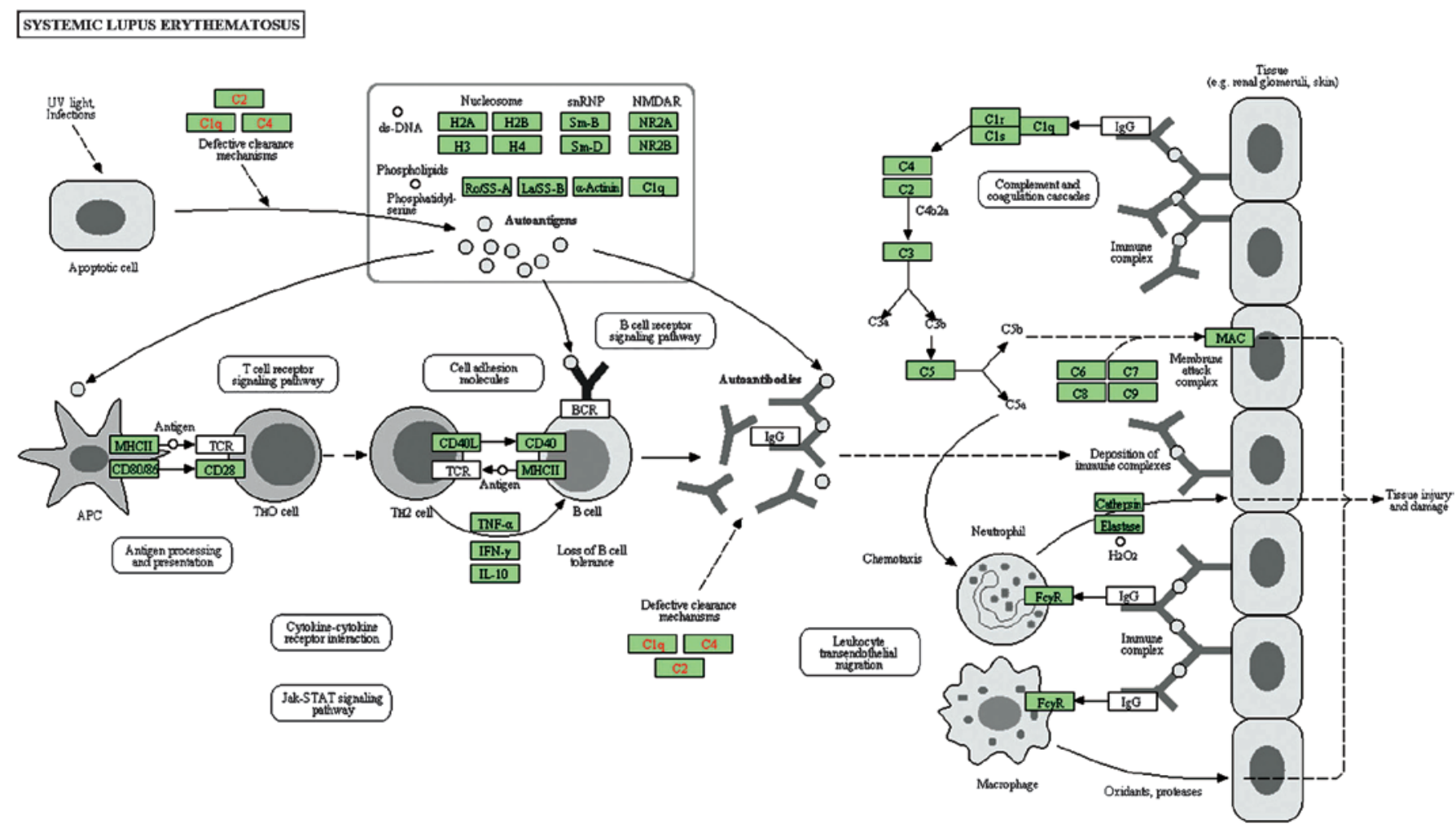

Figure 2. Schematic of the systemic lupus erythematosus pathway in which HLA-DPB1, HIST1H4J, HIST1H2BO, H3F3C, H2AFY, H3F3A, HIST2H3D, HIST1H4D, HIST2H4B, HIST1H2BL and HIST1H4K are involved. IgG, immunoglobulin G; UV, ultraviolet; TCR, T-cell receptor; BCR, B-cell receptor; Fcyr, Fc receptor for $\operatorname{IgG}$.

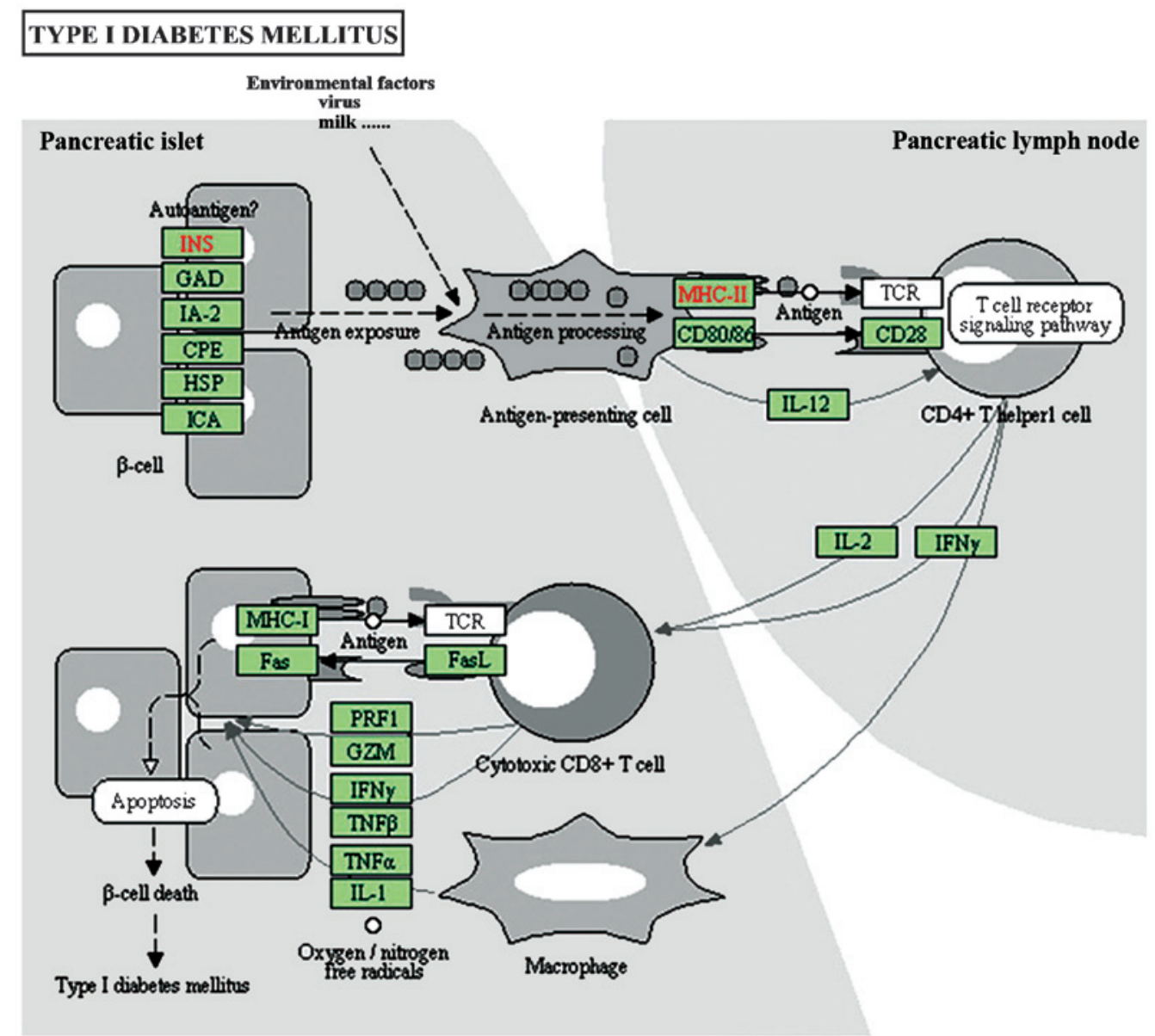

Figure 3. Schematic of the type I diabetes mellitus pathway in which HLA-A, HLA-B, HLA-C, HLA-DPB1 and GAD1 are involved. 
with the risk of lung cancer and Wu et al (22) demonstrated that serum PLP levels were inversely associated with the risk of breast cancer. Overall, this suggested that the genes associated with vitamin B6 binding are involved in tumorigenesis.

Using KEGG analysis, the pathways of SLE and type I diabetes mellitus were identified to be significantly associated with pancreatic cancer. SLE is a systemic autoimmune disease, which can affect any part of the body (23). At present, it is accepted that SLE is associated with an increased risk of certain types of cancer. Previous studies have demonstrated the association between SLE and non-Hodgkin lymphoma (NHL) (24-29) as well as Hodgkin lymphoma (30,31). The risk of NHL was found to be increased by several fold in a SLE population, compared with that of a healthy population (32). Increased risks of breast (29), lung (25,33-37), cervical $(26,29)$ and endometrial cancer (38) in patients with SLE have been observed by cohort studies. Type I diabetes mellitus results from the autoimmune destruction of the insulin-producing cells in the pancreas (39). By meta-analysis, Stevens et al (40) identified an increased risk of pancreatic cancer in a population with type I diabetes mellitus. A population-based cohort study in Sweden conducted by Zendehdel et al (41) demonstrated that patients with type I diabetes mellitus additionally exhibited increased incidences of stomach, cervical and endometrial cancer (41).

In conclusion, the present study suggested that the abnormal expression levels of multiple genes contribute to the incidence of pancreatic cancer. Additional diseases, including type I diabetes and SLE, are closely associated with the tumorigenesis of pancreatic carcinoma. Although the specific functions of these genes with differential expression levels and their mechanisms require further investigation, the results of the present study may aid clinicians in the early diagnosis of pancreatic cancer and in the production of novel targeted therapies.

\section{References}

1. Ghaneh P,Smith R, Tudor-Smith C, Raraty M and Neoptolemos JP Neoadjuvant and adjuvant strategies for pancreatic cancer. Eur J Surg Oncol 34: 297-305, 2008.

2. Sugimura T, Terada M, Yokota J,Hirohashi S and Wakabayashi K: Multiple genetic alterations in human carcinogenesis. Environ Health Perspect 98: 5-12, 1992.

3. Neoptolemos JP, Urrutia R, Abbruzzese JL and Büchler MW: Pancreatic Cancer. Chapter 21: 498-505, 2010.

4. Rafael S, Veganzones S, Vidaurreta M, de la Orden V and Maestro ML: Effect of $\beta$-catenin alterations in the prognosis of patients with sporadic colorectal cancer. J Cancer Res Ther 10: 591-596, 2014.

5. López-Casas PP and López-Fernández LA: Gene-expression profiling in pancreatic cancer. Expert Rev Mol Diagn 10: 591-601, 2010.

6. Maitra A, Kern SE and Hruban RH: Molecular pathogenesis of pancreatic cancer. Best Pract Res Clin Gastroenterol 20: 211-226, 2006.

7. Li Q and Xu W: Novel anticancer targets and drug discovery in post genomic age. Curr Med Chem Anticancer Agents 5: 53-63, 2005.

8. Downward J: Targeting RAS signalling pathways in cancer therapy. Nat Rev Cancer 3: 11-22, 2003.

9. Morris JP IV, Wang SC and Hebrok M: KRAS, Hedgehog, Wnt and the twisted developmental biology of pancreatic ductal adenocarcinoma. Nat Rev Cancer 10: 683-695, 2010.

10. Wang Z, Banerjee S, Ahmad A, Li Y, Azmi AS, Gunn JR, Kong D, Bao B, Ali S, Gao J, et al: Activated K-ras and INK4a/Arf deficiency cooperate during the development of pancreatic cancer by activation of Notch and NF- $\kappa$ B signaling pathways. PLoS One 6 : e20537, 2011
11. Lauth $\mathrm{M}$ and Toftgård R: Hedgehog signaling and pancreatic tumor development. Adv Cancer Res 110: 1-17, 2011.

12. Huang da W, Sherman BT and Lempicki RA: Bioinformatics enrichment tools: paths toward the comprehensive functional analysis of large gene lists. Nucleic Acids Res 37: 1-13, 2009.

13. Biankin AV, Waddell N, Kassahn KS, Gingras MC, Muthuswamy LB, Johns AL, Miller DK, Wilson PJ, Patch AM, Wu J, et al: Pancreatic cancer genomes reveal aberrations in axon guidance pathway genes. Nature 491: 399-405, 2012.

14. Hidalgo M: Pancreatic cancer. N Engl J Med 362: 1605-1617, 2010.

15. Shain AH, Salari K, Giacomini CP and Pollack JR: Integrative genomic and functional profiling of the pancreatic cancer genome. BMC Genomics 14: 624, 2013.

16. Mohr S, Leikauf GD, Keith G and Rihn BH: Microarrays as cancer keys: An array of possibilities. J Clin Oncol 20: 3165-3175, 2002.

17. Chang ZY, Sun R, Ma YS, Fu D, Lai XL, Li YS, Wang XH, Zhang XP, Lv ZW, Cong XL, et al: Differential gene expression of the key signalling pathway in para-carcinoma, carcinoma and relapse human pancreatic cancer. Cell Biochem Funct 32: 258-267, 2014.

18. Nakamura T, Furukawa $Y$, Nakagawa $H$, Tsunoda T, Ohigashi $H$, Murata K, Ishikawa O, Ohgaki K, Kashimura N, Miyamoto M, et al: Genome-wide cDNA microarray analysis of gene expression profiles in pancreatic cancers using populations of tumor cells and normal ductal epithelial cells selected for purity by laser microdissection. Oncogene 23: 2385-2400, 2004.

19. Backman V, Wallace MB, Perelman LT, Arendt JT, Gurjar R, Müller MG, Zhang Q, Zonios G, Kline E, McGilligan JA, et al: Detection of preinvasive cancer cells. Nature 406: 35-36, 2000.

20. Schernhammer E, Wolpin B, Rifai N, Cochrane B, Manson JA, Ma J, Giovannucci E, Thomson C, Stampfer MJ and Fuchs C: Plasma folate, vitamin B6, vitamin B12, and homocysteine and pancreatic cancer risk in four large cohorts. Cancer Res 67: 5553-5560, 2007

21. Johansson M, Relton C, Ueland PM, Vollset SE, Midttun $\varnothing$, Nygård $\mathrm{O}$, Slimani $\mathrm{N}$, Boffetta $\mathrm{P}$, Jenab M, Clavel-Chapelon $\mathrm{F}$, et al: Serum B vitamin levels and risk of lung cancer. JAMA 303: 2377-2385, 2010.

22. Wu W, Kang S and Zhang D: Association of vitamin B6, vitamin B12 and methionine with risk of breast cancer: A dose-response meta-analysis. Br J Cancer 109: 1926-1944, 2013.

23. Dubois EL: The effect of the L. E. cell test on the clinical picture of systemic lupus erythematosus. Ann Intern Med 38: 1265-1294, 1953.

24. Smedby KE, Hjalgrim H, Askling J, Chang ET, Gregersen H, Porwit-MacDonald A, Sundström C, Akerman M, Melbye M, Glimelius B, et al: Autoimmune and chronic inflammatory disorders and risk of non-Hodgkin lymphoma by subtype. J Natl Cancer Inst 98: 51-60, 2006.

25. Björnådal L, Löfström B, Yin L, Lundberg IE and Ekbom A: Increased cancer incidence in a Swedish cohort of patients with systemic lupus erythematosus. Scand J Rheumatol 31: 66-71, 2002.

26. Cibere J, Sibley J and Haga M: Systemic lupus erythematosus and the risk of malignancy. Lupus 10: 394-400, 2001.

27. Pettersson T, Pukkala E, Teppo L and Friman C: Increased risk of cancer in patients with systemic lupus erythematosus. Ann Rheum Dis 51: 437-439, 1992.

28. Bernatsky S, Ramsey-Goldman R, Rajan R, Boivin JF, Joseph L, Lachance S, Cournoyer D, Zoma A, Manzi S, Ginzler E, et al: Non-Hodgkin's lymphoma in systemic lupus erythematosus. Ann Rheum Dis 64: 1507-1509, 2005.

29. Ramsey-Goldman R, Mattai SA, Schilling E, Chiu YL, Alo CJ, Howe HL and Manzi S: Increased risk of malignancy in patients with systemic lupus erythematosus. J Investig Med 46: 217-222, 1998.

30. Bernatsky S, Ramsey-Goldman R, Isenberg D, Isenberg D, Rahman A, Dooley MA, Sibley J, Boivin JF, Joseph L, Armitage J, et al: Hodgkin's lymphoma in systemic lupus erythematosus. Rheumatology (Oxford) 46: 830-832, 2007.

31. Landgren O, Engels EA, Pfeiffer RM, Gridley G, Mellemkjaer L, Olsen JH, Kerstann KF, Wheeler W, Hemminki K, Linet MS, et al: Autoimmunity and susceptibility to Hodgkin lymphoma: A population-based case-control study in Scandinavia. J Natl Cancer Inst 98: 1321-1330, 2006.

32. Gayed M, Bernatsky S, Ramsey-Goldman R, Clarke A and Gordon C: Lupus and cancer. Lupus 18: 479-485, 2009.

33. Bernatsky S, Boivin JF, Joseph L, Manzi S, Ginzler E, Gladman DD, Urowitz M, Fortin PR, Petri M, Barr S, et al: Mortality in systemic lupus erythematosus. Arthritis Rheum 54: 2550-2557, 2006. 
34. Thomas E, Brewster DH, Black RJ and Macfarlane GJ: Risk of malignancy among patients with rheumatic conditions. Int J Cancer 88: 497-502, 2000.

35. Mellemkjér L, Andersen V, Linet MS, et al: Non-Hodgkin's lymphoma and other cancers among a cohort of patients with systemic lupus erythematosus. Arthritis Rheum 40: 761-768, 1997.

36. Bernatsky S, Ramsey-Goldman R and Clarke AE: Revisiting the issue of malignancy risk in systemic lupus erythematosus. Curr Rheumatol Rep 7: 476-481, 2005.

37. Ruiz-Irastorza G, Ugarte A, Egurbide MV, Garmendia M, Pijoan JI, Martinez-Berriotxoa A and Aguirre C: Antimalarials may influence the risk of malignancy in systemic lupus erythematosus. Ann Rheum Dis 66: 815-817, 2007.
38. Bernatsky S, Boivin JF, Joseph L, Rajan R, Zoma A, Manzi S, Ginzler E, Urowitz M, Gladman D, Fortin PR, et al: An international cohort study of cancer in systemic lupus erythematosus. Arthritis Rheum 52: 1481-1490, 2005.

39. Akerblom HK and Knip M: Putative environmental factors in Type 1 diabetes. Diabetes Metab Rev 14: 31-67, 1998.

40. Stevens RJ, Roddam AW and Beral V: Pancreatic cancer in type 1 and young-onset diabetes: Systematic review and meta-analysis. Br J Cancer 96: 507-509, 2007.

41. Zendehdel K, Nyrén O, Ostenson CG, Adami HO, Ekbom A and Ye W: Cancer incidence in patients with type 1 diabetes mellitus: A population-based cohort study in Sweden. J Natl Cancer Inst 95: 1797-1800, 2003. 